\title{
EFEKTIFITAS PESAN DAKWAH TERHADAP PENINGKATAN BEHAVIORISME ANAK
}

\section{Murniati}

Fakultas Dakwah dan Komunikasi UNISNU Jepara Jl. Taman Siswa Tahunan Jepara

murniati@unisnu.ac.id

\section{Abstract}

The title of this research is the Effectiveness of Dakwah Message towards Increasing Child Behaviorism in learning sentra Iman Taqwa at KB PAUD Mutiara 2016. This research is aimed at finding out how far the effectiveness of Dakwah message packaged in preparing a playful environment in Sentra Iman dan Taqwa at KB Mutiara Karanggondang. The schedule of the sentra is repeated every two weeks. The method of this research is Classroom Action Research. The activity of this research is about four months. The researcher conducts two cycles in order to find out the data. The first cycle conducts on July to August. The second cycle conducts on September to October. The result of this research showed that the Dakwah message package in Sentra Iman Taqwa learning is sufficiently effective for increasing the child behaviorism.

Keywords : Dakwah message, behaviorism, Sentra Iman Taqwa

\section{Abstrak}

Penelitian tentang “Efektifitas Pesan Dakwah terhadap Peningkatan Behaviorisme Anak pada Pembelajaran Sentra Iman Taqwa di KB. PAUD Mutiara Tahun 2016", bertujuan untuk mengetahui sejauhmana tingkat efektifitas pesan dakwah yang dikemas dalam penyiapan lingkungan main pada pembelajaran Sentra Iman Taqwa di KB. PAUD Mutiara Karanggondang, dimana penjadwalan sentra akan berulang setiap dua minggu sekali. Metodologi penelitian yang digunakan adalah Penelitian Tindakan Kelas, dimana peneliti akan menemukan data berdasarkan siklus 1 san siklus 2. Ditentuka dari jadwal pengajaran yaitu per dua minggu sekali selama 4 bulan yang dibagi berdasarkan data siklus 1 yaitu dilakukan dalam dua bulan pertama yaitu bula Juli sampai Agustus 2016 dan data siklus 2 yaitu dilakukan dalam bulan terakhit yaitu bulan September dan bulan Oktober.

Kata Kunci : Pesan Dakwah, Behaviorisme, Sentra Iman Taqwa 


\section{A. PENDAHULUAN}

Pada dasarnya pendidikan anak usia dini (PAUD) dicanangkan pemerintah melalui UU. RI. No. 20 tahun 2003 adalah sebagai upaya pembinaan yang mutlak dibutuhkan anak sejak lahir. Upaya yuridis ini bertujuan agar hak anak Indonesia terpenuhi hajat hidupnya dan dalam menyiapkan generasi emas tahun 2045.

Secara sistematis dan gradual pendidikan anak usia dini dirancang untuk menstimulasi dan merangsang perkembangan potensi anak agar beriman dan bertaqwa kepada Tuhan Yang Maha Esa, berakhlak mulia, sehat, berilmu, cakap, kritis, kreatif, inovatif, mandiri, percaya diri dan menjadi warga negara yang bertanggung jawab (Suyadi, 2014:24). Sedangkan komponen dasar agar anak sesuai yang diharapkan yaitu mempunyai karakter yang bagus yang tercermin dalam efek behaviorisme yang maksimal. Paling tidak harus ada tiga aspek perkembangan yang harus distimuli dan difasilitasi dengan tepat. Tiga aspek yang menunjang behaviorisme anak akan tumbuh dengan maksimal, diantaranya, pertama, aspek kognitif, kedua, aspek afeksi dan ketiga, aspek psikomotorik.

Semua aspek tersebut dibutuhkan sebagai upaya pemaksimalan dalamwilayah pendidikan dan pengajaran yang dimulai dari usia dini. Pendidikan dan pengajaran pada usia dini juga membutuhkan sentuhan dakwah dalam artian yang luas yaitu sebagai upaya mengajak amar ma'ruf nahi munkar dengan menggunakan metode dan media tarbiyah, sehingga upaya mengajak kebaikan dan menjauhi kemungkaran bisa dikemas dengan baik melalui media pembelajaran.

Teori behaviorisme yang dikembangkan oleh John B. Watson mengatakan bahwa behavioristik merupakan teori yang orientasinya didasarkan pada premis bahwa psikologi ilmiah harus berdasarkan studi tingkah laku yang teramati (observeable behavior). Lebih lanjut para ahli psikologi semisal Freud memandang kepribadian individu adalah kolektifitas kecenderungan yang merespon berbagai stimulasi yang beragam. Dalam hal ini baik Freud maupun Dollar dan Miller (1950) sama-sama sependapat tentang pentingnya pengalaman sejak kecil (Yusuf, 2013:123124).

Kebutuhan perangsangan kerohaniahan diharapkan agar anak mempunyai sifat dan karakter yang baik, harus diciptakan dalam usaha mepengaruhi pandangan, pendapat, sikap dalam mengubah perilaku seseorang. Pemilihan metode dan media pembelajaran yang tepat sangat mendukung terangsangnya fungsi otak secara maksimal. Dan perlu disadari bersama bahwa dunia anak adalah bermain, dunia anak yang menyenangkan adalah ketika anak dibiarkan beraktifitas dan berkreatifitas sesuai dengan bakat dan minatnya. Karena setiap anak adalah individu yang unik yang mempunyai potensi yang berbeda-beda satu dengan yang lainnya, namun saling melengkapi dan berharga. Pendekatan behaviorisme idealnya dilakukan sejak anak usia dini karena melalui pesan-pesan dakwah yang dikemas dengan media dan metode pembelajaran yang tepat akan berefek pada pola tingkah 
laku yang tercermin dalam laku melalui pesan dakwah.

Pemahamanterhadapeksistensibahwa anak merupakan individu yang unik sangat dibutuhkan, disamping ada catatan bahwa anak adalah anak, bukan orang dewasa yang mini (Susanto, 2011:2). Probelamatika yang muncul pada pembelajaran anak usia dini adalah bahwa anak mempunyai rentang perhatian yang terbatas dan masih sulit diatur atau masih sulit belajar dengan "serius" tetapi bila pengenalan konsepkonsep tersebut dilakukan sambil bermain maka anak akan merasa senang dan tidak sadar bahwa sejatinya dia sudah banyak belajar (Tedjasaputra, 2007:43).

Model pembelajaran sentra dalam kenyataannya ternyata efektif dan efisien diterapkan pada pendidikan anak usia dini. Kemasan yang terdapat dalam Sentra Iman Taqwa dirancang untuk merangsang kognisi, afeksi dan psikomotorik. Efek yang ditimbulkan kematangan behavioreisme anak bisa terealisasi melalui pesan dakwah.

Hal itu penting karena merupakan suatu yang fundamental dan yang membimbing tingkah laku anak. Kuncinya terletak pada bagaimana pengetahuan tersebut terstruktur dalam berbagai aspeknya (Susanto, 2011:23).

Tujuan dari penelitian ini diharapkan dapat menguji efektifitas pesan dakwah yang dikemas dalam kegiatan sentra. Kegiatan sentra dipersiapkan untuk mengasah sensitifitas anak dalam rangka meningkatkan daya kognisi, afeksi dan psikomotorik anak sehingga behaviorisme anak dapat tertata dengan maksimal.
Kajian pustaka dilakukan agar tema kajian yang dilakukan memiliki signifikansi yang jelas berkaitan dengan kajian-kajian sebelumnya. Beikut literatur yang peneliti temukan pada pendidikan anak usia dini (PAUD) dalam kaitannya dengan kajian ini:

Pertama, penelitian yang dilakukan oleh Wisjnu Martani yang dipublikasi pada Jurnal Psikologi, volume 39, No.1. Juni 2012 : 112-120 yang berjudul; Metode Stimulasi dan Perkembangan Emosi, menemukan bahwa cara yang dipakai untuk menstimuli perkembangan emosi anak tidak ada yang spesifik. Guru/ tutor PAUD menggunakan cara dan aturan baku yang sudah ada dalam panduan akademik untuk menstimulasi anak dengan menggunakan media benda seperti balok, buku cerita, VCD/kaset dalam rangka mengasah kemampuan kognisi anak.

Kedua, penelitian yang dilakukan oleh Yulia Sari, berjudul Manajemen Pembelajaran Sentra dan Lingkaran Pada PAUD Subulussalam Kota Banda Aceh. Temuan penelitiannya adalah tehnis pembelajaran sentra dilaksanakan dengan pola pembelajaran berpusat pada anak, anak dalam posisi duduk melingkar dengan menggunakan empat pijakan main yaitu (a) pijakan lingkungan main, (b) pijakan sebelum main, (c) pijakan selama main, dan (d) pijakan setelah main. Dan diakhir kegiatan main dilakukan evaluasi terhadap aspek-aspek perkembangan anak yang meliputi: nilai-nilai agama dan moral, motorik, kognitif, bahasa dan sosial Emosional. 


\section{B. METODE PENELITIAN}

Penelitian ini merupakan penelitian kualitatif dengan model pendekatan tindakan kelas. Sebagaimana pendapat Strauss dan Corbin (2007:4) mengatakan bahwa penelitian kualitatif dimaksudkan sebagai jenis penelitian yang temuantemuannya tidak diperoleh melalui prosedur temuan statistik atau dalam bentuk hitungan. Model tindakan kelas peneliti gunakan sebagai upaya untuk memahami atau menafsirkan fenomena dilihat dari sisi makna yang melekat pada manusia (peneliti) dan subyek yang dikaji dan kumpulan berbagai data empiris---studi kasus, pengalaman pribadi, introspeksi, perjalanan hidup, wawancara, teks-teks hasil pengamatan, historis, interaksional dan visual yang menggambarkan saat-saat dan makna keseharian serta probematika kehidupan seseorang (Putra, Dwilestari, 2013:67).

Penelitian tidakan kelas adalah merupakan kajian sistematik tentang upaya praktik pendidikan oleh sekelompok orang melalui tindakan praktis yang mereka lakukan dan merefleksikan tindakannya (Hopins,1993, dalam Nadhiroh, 2015)

Setting penelitian ini bertempat di KB PAUD Mutiara Karangggondang, Mlongo, Jepara. Waktu penelitian ini dilaksanakan antara bulan Juli- Oktober 2016. Adapun subyek penelitian tindakan kelas ini adalah semua siswa KB PAUD Mutiara tahun ajaran 2015-2016. Sedangkan sumber data dalam penelitian tindakan kelas ini adalah semua peserta didik, guru Sentra Iman dan Taqwa dan kepala sekolah KB PAUD Mutiara.
Adapun teknik dan alat pengumpulan data yang digunakan dalam penelitian ini antara lain: Pertama, penugasan. Penugasan dilakukan dalam bentuk peciptaan lingkungan main melalui kegiatan main di Sentra Iman Taqwa. Siklus pengulangan Sentra Iman dan Taqwa dilakukan dua minggu sekali. Kedua, Observasi. Observasi dilakukan untuk memperoleh data kemampuan peningkatan behaviorisme anak melalui kegiatan main lewat penciptaan lingkungan main Sentra Iman dan Taqwa. Ketiga, Dokumentasi adalah suatu metode yang digunakan untuk mencari data berkaitan dengan hasil karya, penilaian, weekly raport, buku agenda dan lain sebagainya yang berkaitan dengan hasil akhir proses main anak. Keempat, Wawancara. Wawancara merupakan tehnik pengumpulan data yang paling mendukung terjadinya proses pengumpulan data yang representatif dan mengupas lebih mendalam dan sebagai verifikasi data mengenai apa yang peneliti observasi dengan data yang akan diobservasi kemudian (Setiawan, 2014:98).

Keabsahan data atau validitas datanya menggunakan trianggulasi antara lain: Trianggulasi sumber yaitu tanya jawab langsung dengan guru untuk mengetahui sejauh mana pembelajaran Sentra Iman dan Taqwa dapat meningkatkan behaviorisme anak. Dan trianggulasi alat yaitu alat yang digunakan dalam kegiatan pembelajaran Sentra Iman dan Taqwa. Sedangkan penelitian tindakan kelas ini dinyatakan berhasil apabila memenuhi indikator keberhasilan. Adapun indikator keberhasilannya sebagai berikut: Guru terampil dalam menentukan fokus belajar 
yang sesuai dengan minat dan kebutuhan siswa dengan aktifitas guru minimal baik dalam lembar observasi.Terjadi perubahan sikap dan perilaku serta keterampian siswa melalui kegiatan Sentra Iman dan Taqwa meningkat ditandai dengan aktifitas siswa minimal baik dalam lembar observasi. Dan $75 \%$ siswa mengalami ketuntasan belajar.

Analisis data dalam penelitian tindakan kelas ini menggunakan analisis kualitatif. Kegiatan di Sentra Iman Taqwa dianalisis dengan cara kualitatif dengan memberikan skor (1, 2 dan 3). Data-data tersebut dianalisis mulai dari siklus 1 dan siklus 2 untuk membandingkan perolehan nilai rata-ratanya.

Hasil perhitungan dikonsultasikan dengan tabel kriteria diskriptif presentasi, yang dikelompokkan dalam tiga kategori yaitu, baik, cukup, kurang.

\begin{tabular}{lll}
\hline Kriteria & Skor & Penafsiran \\
\hline Baik & $71 \%-85 \%$ & Perkembangan behaviorisme baik \\
Cukup & $56 \%-70 \%$ & Perkembangan behaviorisme cukup \\
Kurang & $<55 \%$ & Perkembangan behaviorisme kurang \\
\hline
\end{tabular}

\section{HASIL DAN PEMBAHASAN}

Dakwah merupakan kegiatan yang mempunyai tujuan amar ma'ruf nahi munkar. Menurut Thoha Yahya yang dikutip Najamuddin menjelaskan bahwa dakwah adalah mengajak manusia dengan cara yang bijaksana kejalan yang sesuai dengan perintah Allah, demi kemaslahatan dan kebahagiaan manusia di dunia maupun di akhirat (Najamuddin, 2008:1).

Pada proses kegiatan belajar mengajar yang terdapat pada pembelajaran anak usia dini, proses yang sangat penting yaitu terletak pada kurikulum pendidikan yang diejawentahkan guru dalam aktifitas pembelajaran sehari-hari. Dalam pembelajaran senta Iman Taqwa di KB. PAUD Mutiara banyak menggunakan kurikulum yang mengacu pada muatan lokal yang disesuaikan denga visi dan misi yang dimiliki KB.PAUD Mutiara. Capaian yang di rencanakan dalam pembelajaran sentra Iman Taqwa adalah kompetensi dasar yang harus dimiliki anak-anak KB. PAUD Mutiara tentang muatan ideologis sebagaiamana konsepsi keimanan dan keislaman.

Kegiatan yang disusun dalam pembelajaran sentra Iman Taqwa terbagi dalam tiga tahapa kegiatan, yaitu kegiatan sebelum main, adalah kegiatan stimuli otak dan pembiasaan yang menjadi budaya sekolah. Untuk sentra Iman Taqwa kegiatan yang dilakukan adalah anak diajak kehalaman dan membuat lingkaran besar. Di dalam lingkaran besar semua anak KB. PAUD Mutiara berkesempatan saling berinteraksi antara kelompok usia, baik PG 1, PG 2, PG3 dan PG 4. Materi yang diberikan pada lingkaran besar biasanya permainan 
(Role Play), senam otak, dan lagu-lagu anak yang dikemas dengan lirik islami semisal sholawat dan do'a-do'a pendek.

Adapun kegiatan main secara keseluruhan direncanakan dalam RPPH (Rencana Pelaksanaan Program Harian) dengan capaian pembelajaran yang dikategorikan dalam kelompok usia, yaitu: Kelompok A (PG 1 dan 2) dan kelompok B (PG 3 dan 4).

\section{Paparan Data Siklus 1}

Data siklus 1 dihasilkan dari hasil pengumpulan data 2 bulan pertama yaitu antara bulan Juli dan Agustus 2016 pada pembelajaran sentra di masing-masing kelompok PG. Adapun tehnik yang digunakan adalah penugasan, observasi, dokumentasi dan wawancara.

1. Penyusunan rencana siklus 1 pada kelompok A PG 1

Penelitian tindakan kelas ini meliputi kegiatan awal, kegiatan inti, dan kegiatan akhir. Pelaksanaan tindakan mengacu pada pijakan lingkungan yang telah dipersiapkan guru pada tahapan main.

Pada tanggal 26 Juli 2016, pijakan main yang disiapkan guru adalah :

a. Menulis huruf arab $a$, alat yang digunakan adalah kertas HVS dan pensil.

b. Menebak, alat yang digunakan adalah kitab Qira,ati jilid pra.

c. Meronce, alat yang digunakan adalah roncean huruf dan angka arab. Tali dari benang kong.

d. Menyambung titik huruf dan angka arab, alat pensil.
Pada tanggal 8 Agustus 2016 , pijakan main yang disiapkan guru adalah:

a. Menulis huruf arab $b a$, alat yang digunakan kertas HVS dan pensil.

b. Meronce huruf hijaiyah, alat yang digunakan roncean huruf hijaiyah dan benang kong.

c. Mencocok angka arab dua, alat yang digunakan pensil.

d. Menjepit huruf dan angka arab, alat yang digunakan penjepit baju, benag kong dan kartu.

Siklus 1 berisi tentang lembar penilaian anak atau rangkuman penilaian anak selama 2 bulan pertama yaitu bulan Juli dan Agustus. Terdapat 6 aspek/ indikator yang berkaiatan dengan pesan dakwah dalam meningkatkan behaviorisme anak melalui kegiatan sentra Iman Taqwa. Penilaian dilakukan guru dengan menyediakan pijakan main sesuai $\mathrm{RPPH}$ (Rencana Pelaksanaan Program Harian). Hasil aktifitas main didokumentasikan dalam Weekly Raport (Laporan kegiatan pembelajaran mingguan). Adapun prosentase hasil belajar anak diakumulasi pada tabel prosentasi hasil belajar anak sebagai berikut: 
Tabel 1. Prosentasi Hasil Belajar Anak pada Siklus 1

\begin{tabular}{|l|c|c|c|}
\hline \multicolumn{1}{|c|}{ Indikator } & \multicolumn{3}{|c|}{ Nilai (\%) } \\
\cline { 2 - 4 } & Baik & Cukup & Kurang \\
\hline $\begin{array}{l}\text { Hafal dua kalimah } \\
\text { Syahadat }\end{array}$ & 100 & - & - \\
\hline $\begin{array}{l}\text { Mengetahui gerakan } \\
\text { sholat }\end{array}$ & 90 & 10 & - \\
\hline $\begin{array}{l}\text { Mengenal huruf } \\
\text { hijaiyah dan angka } \\
\text { arab }\end{array}$ & 80 & - & - \\
\hline $\begin{array}{l}\text { Taat pada orang tua } \\
\text { dan bu guru }\end{array}$ & 80 & 10 & 10 \\
\hline $\begin{array}{l}\text { Sayang pada teman } \\
\text { dan mau berbagi } \\
\text { dengan teman }\end{array}$ & 80 & 10 & 10 \\
\hline Hafal rukun Islam & 100 & - & - \\
\hline
\end{tabular}

Temuan pada siklus 1 pesan dakwah yang dikemas dalam Sentra Iman Taqwa dapat meningkatkan behaviorisme anak dengan penilaian menunjukkan hasil baik dengan bobot 530 point dari target maksimal 600 point.

2. Penyusunan rencana siklus 1 pada kelompok A PG 2

Pelaksanaan tindakan mengacu pada pijakan lingkungan yang dipersiapkan guru pada tahapan main.

Pada tangal 2 Agustus 2016, pijakan lingkungan yang disipakan guru adalah:

a. Menulis huruf $a, b a$, alat yang digunakan guru adalah spidol warna dan kertas HVS.

b. Meronce huruf arab, alat yang disediakan guru adalah roncean dan tali.

c. Menulis angka arab 1, alat yang disediakan guru adalah kertas dan spidol warna.

d. Menyambung titik, alat yang digunakan adalah kertas dan spidol warna.

Pada tanggal 16 Agustus 2016 pijakan lingkungan yang dilakukan adalah:

a. Menyambung titik huruf $a, b a$, alat yang disediakan guru adalah kertas dan spidol.

b. Mengurutkan dan menempel angka $\operatorname{arab} 1,2,3$, alat yang digunakan adalah kertas bertulis angka 1, 2, 3, kertas dan lem.

c. Menjepit huruf hijaiyah, alat yang disediakan guru adalah jepitan, tali dan huruf hijaiyah.

Hasil observasi dan pencatatan data siklus pada kelompok A PG 2 pada siklus 1 bahwa berdasarkan perangsangan yang dikemas pada pembelajaran sentra Iman Taqwa dengan media dan metode yang dikemas dengan pesan dakwah dapat mempermudah membentuk behaviorisme anak. Hal ini bisa digambarkan pada tabel prosentase hasil belajar anak kelompok $\mathrm{A}$ Pg 2. 
Tabel 2. Prosentase Hasil Belajar Anak Kelompok A Pg 2

\begin{tabular}{|l|c|c|c|}
\hline \multirow{2}{*}{ Indikator } & \multicolumn{3}{|c|}{ Nilai (\%) } \\
\cline { 2 - 4 } & Baik & Cukup & Kurang \\
\hline $\begin{array}{l}\text { Hafal dua kalimah } \\
\text { Syahadat }\end{array}$ & 100 & - & - \\
\hline $\begin{array}{l}\text { Mengetahui gerakan } \\
\text { sholat }\end{array}$ & 90 & 10 & - \\
\hline $\begin{array}{l}\text { Mengenal huruf } \\
\text { hijaiyah dan angka } \\
\text { arab }\end{array}$ & 90 & 10 & 10 \\
\hline $\begin{array}{l}\text { Taat pada orang tua } \\
\text { dan bu guru }\end{array}$ & 80 & 10 & \\
\hline $\begin{array}{l}\text { Sayang pada teman } \\
\text { dan mau berbagi } \\
\text { dengan teman }\end{array}$ & 100 & - & - \\
\hline Hafal rukun Islam & & & \\
\hline
\end{tabular}

Temuan penelitian pada siklus 1 kelompok A PG 2 menunjukkan bahwa aktifitas main yang dikemas dalam sentra Iman Taqwa cukup signifikan dalam mempengaruhi behaviorisme anak, terbukti dengan bobot 530 poin dari target maksimal 600 poin.

3. Penyusunan rencana siklus 1 pada kelompok B PG 3

Pelaksanaan tindakan mengacu pada pijakan lingkungan yang dipersiapkan guru pada tahapan main.

Pada tanggal 2 Agustus 2 Agustus 2016 pijakan lingkungan yang disiapkan guru adalah:

a. Membaca huruf hijaiyah dengan alat tulis dan peraga

b. Kegiatan menjepit huruf hijaiyah dengan alat jepitan baju dan potongan tulisan huruf hijaiyah

c. Menulis huruf hijaiyah dengan alat kertas dan spidol warna. Dilanjutkan pijakan setelah main meliputi: beresberes, recalling tema, membaca doa keluar rumah, dilanjutkan dengan dzikir membaca surat al-Fatikhah dan shalawat badar.

Pada tanggal 30 Agustus 2016, pijakan lingkungan yang disediakan guru adalah:

a. Mengarsir angka arab 2 dengan alat kertas, pensil dan krayon.

b. Membaca niat sholat, dengan tulisan peraga.

c. Menempel huruf arab a, ba, dengan alat kertas dan potongan tulisan huruf arab. Dilanjutkan kegiatan beres-beres, dzikir, halawat badar, membaca surat al-Ikhlas dan membaca doa sebelum tidur bersama-sama.

Hasil observasi dan pencatatan data siklus 1 pada Kelompok B PG 3, dilakukan pada bulan Juli-Agustus 2016 pada pembelajaran sentra Iman Taqwa. Ada 6 
aspek/indikator berkaitan dengan pesan dakwah yang dikemas dalam sentra Iman Taqwa. Guru menyediakan pijakan main sesuai capaian RPPH (Rencana Pelaksanaan Program Harian). Adapun prosentase hasil belajar anak diakumulasi pada tabel prosentase hasil belajar anak kelompok B PG 3.

Tabel. 3. Prosentase Hasil Belajar Anak Kelompok B PG 3

\begin{tabular}{|l|c|c|c|}
\hline \multicolumn{1}{|c|}{ Indikator } & \multicolumn{3}{|c|}{ Nilai (\%) } \\
\cline { 2 - 4 } & 100 & Cukup & Kurang \\
\hline $\begin{array}{l}\text { Hafal dua kalimah } \\
\text { Syahadat }\end{array}$ & 90 & 10 & - \\
\hline $\begin{array}{l}\text { Mengetahui gerakan } \\
\text { sholat }\end{array}$ & 100 & & - \\
\hline $\begin{array}{l}\text { Mengenal huruf } \\
\text { hijaiyah dan angka } \\
\text { arab }\end{array}$ & 80 & 10 & 10 \\
\hline $\begin{array}{l}\text { Taat pada orang tua } \\
\text { dan bu guru }\end{array}$ & 90 & 10 & - \\
\hline $\begin{array}{l}\text { Sayang pada teman } \\
\text { dan mau berbagi } \\
\text { dengan teman }\end{array}$ & 100 & - & - \\
\hline Hafal rukun Islam & & & \\
\hline
\end{tabular}

Temuan sementara pada siklus 1 kelompok B PG 3 adalah pesan dakwah yang dikemas dalam pembelajara sentra Iman Taqwa cukup efektif mempengaruhi behaviorisme anak terbukti dengan bobot nilai 560 pin dari target maksimal 600 poin.

4. Penyusunan rencana siklus 1 pada kelompok B PG 4

Pelaksanaan tindakan mengacu pada pijakan lingkungan yang disiapkan guru pada tahapan main.

Pada tanggal 8 Agustus 2016 pijakan lingkungan yang disediakan guru adalh:

a. Menulis huruf dan angka arab, dengan alat kertas dan pensil.

b. Menempel bentuk geometri bertuliskan huruf dan angka arab sesuai capaian, dengan alat kertas geometri, lem dan kertas kosong.

c. Menjepit, alat yang digunakan kartu huruf dan angka, jepitan baju dan benang kong.

Hasil observasi dan pencatatan data siklus 1 berisi tentang lembar penilaian pada anak atau rangkuman penilaian anak selama 2 bulan pertama yaitu bulan Juli dan Agustus pada jadwal sentra Iman Taqwa. Guru melakukan penilaian hasil dari proses pembelajaran tentang pesan dakwah yang dikemas dalam sentra Iman Taqwa dalam aktifitas main. Guru menyediakan pijakan main sesuai capaian RPPH (Rencana Pelaksanaan Program 
Harian). Hasil penilaian didokumentasikan dalam Weekly Raport ( Laporan kegiatan mingguan). Adapun prosentase hasil belajar anak diakumulasi pada tabel prosentase akumulasi hasil belajar anak. kelompok A $\operatorname{Pg} 4$

Tabel 4. Prosentase akumulasi hasil belajar anak kelompok A Pg 4

\begin{tabular}{|l|c|c|c|}
\hline \multicolumn{1}{|c|}{ Indikator } & \multicolumn{3}{|c|}{ Nilai (\%) } \\
\cline { 2 - 4 } & Baik & Cukup & Kurang \\
\hline $\begin{array}{l}\text { Hafal dua kalimah } \\
\text { Syahadat }\end{array}$ & 100 & - & - \\
\hline $\begin{array}{l}\text { Mengetahui gerakan } \\
\text { sholat }\end{array}$ & 100 & - & - \\
\hline $\begin{array}{l}\text { Mengenal huruf } \\
\text { hijaiyah dan angka } \\
\text { arab }\end{array}$ & 100 & - & - \\
\hline $\begin{array}{l}\text { Taat pada orang tua } \\
\text { dan bu guru }\end{array}$ & 90 & 10 & - \\
\hline $\begin{array}{l}\text { Sayang pada teman } \\
\text { dan mau berbagi } \\
\text { dengan teman }\end{array}$ & 90 & 10 & - \\
\hline Hafal rukun Islam & 100 & - & - \\
\hline
\end{tabular}

Temuan sementara bahwa katifitas main yang dikmas dalam pembelajaran sentra Iman Taqwa kelompok B PG 4 cukup efektif dalam mempengaruhi behaviorisme anak terbukti dengan bobot 580 poin dari target maksimal 600 poin.

\section{Paparan Data Siklus 2}

Data siklus 2 dihasilkan dari hasil pengumpulan data 2 bulan terakhir yaitu antara bulan September dan Oktober 2016 pada pembelajaran sentra di masingmasing kelompok PG. Adapun tehnik yang digunakan adalah penugasan, observasi, dokumentasi dan wawancara.

1. Penyusunan rencana siklus 2 pada kelompok A PG 1

Pelaksanaan tindakan mengacu pada pijakan lingkungan yang dipersiapkan guru pada tahapan main.
Pada tanggal 5 September 2016 pijakan lingungan yang disediakan guru adalah:

a. Mengarsir, alat yang disediakan guru adalah tulisan huruf dan angka arab di kertas HVS dan pensil'

b. Menulis huruf arab a, ba, ta. Alat yang disediakan guru kertas HVS dan pensil.

c. Menjiplak, alat yang disediakan guru kertas HVS, balok huruf dan angka arab.

Pada tanggal 19 September, pijakan lingkungan yang disediakan guru adalah:

a. Menulis angka tiga arab, alat yang disediakan guru adalah kertas HVS dan pensil.

b. Menyambung titik, ta, tsa, alat yang disediakan kertas HVS dan pensil.

c. Menebak huruf a sampai ta, alat yang digunakan balok huruf dan angka arab. 
d. Meronce, alat yang digunakan roncean kayu.

Pada tanggal 3 Oktober 2016 pijakan lingkungan yang disediakan guru adalah:

a. Menulis huruf a, ba, ta, alat yang disediakan guru adalah kertas HVS dan pensil.

b. Kolase, alat yang digunakan guru, kertas HVS, kertas perca dan lem.

c. Meronce, alat yang digunakan adalah roncean.

d. Membaca, alat yang disediakan guru adalah kitab qira'ati jilid pra.

Pada tanggal 17 Oktober 2016 pijakan lingkunga yang disediakan guru adalah:

a. Menjepit huruf dan angka arab, alat yang disediakan adalah 2 jepitan, kertas bertuliskan angka dan huruf arab, benang kong.

b. Membaca, alat yang disediaakan guru kitab qira'ati jilid pra. c. Menulis huruf ta, tsa, alat yang disediakan guru adalah kertas HVS dan pensil.

d. Menebak angka, alat yang digunakan balok angka arab.

Hasil observasi dan pencatatan data siklus 1 berisi tentang lembar penilaian pada anak atau rangkuman penilaian anak selama 2 bulan kedua yaitu bulan September dan Oktober pada jadwal sentra Iman Taqwa. Guru melakukan penilaian hasil dari proses pembelajaran tentang pesan dakwah yang dikemas dalam sentra Iman Taqwa dalam aktifitas main. Guru menyediakan pijakan main sesuai capaian RPPH (Rencana Pelaksanaan Program Harian). Hasil penilaian didokumentasikan dalam Weekly Raport ( Laporan kegiatan mingguan). Adapun prosentase hasil belajar anak diakumulasi pada tabel prosentase akumulasi hasil belajar anak. kelompok A $\operatorname{Pg} 1$.

Tabel 5. Prosentase Akumulasi Hasil Belajar Anak. Kelompok a pg 1.

\begin{tabular}{|l|c|c|c|}
\hline \multirow{2}{*}{\multicolumn{1}{|c|}{ Indikator }} & \multicolumn{3}{c|}{ Nilai (\%) } \\
\cline { 2 - 4 } & Baik & Cukup & Kurang \\
\hline $\begin{array}{l}\text { Hafal dua kalimah } \\
\text { syahadat }\end{array}$ & 100 & - & - \\
\hline Mengetahui gerakan sholat & 90 & 10 & - \\
\hline $\begin{array}{l}\text { Mengetahui arti puasa dan } \\
\text { bisa mempraktekkannya }\end{array}$ & 90 & - & - \\
\hline $\begin{array}{l}\text { Mengenal huruf hijaiyah } \\
\text { dan angka arab }\end{array}$ & 100 & & \\
\hline $\begin{array}{l}\text { Taat pada orang tua dan } \\
\text { bu guru }\end{array}$ & 90 & 10 & \\
\hline $\begin{array}{l}\text { Sayang pada teman dan } \\
\text { mau berbagi dengan teman }\end{array}$ & 90 & - & - \\
\hline Hafal rukun Islam & 100 & & \\
\hline
\end{tabular}


Temuan sementara bahwa aktifitas main yang dikemas dalam pembelajaran sentra Iman Taqwa kelompok A PG 1 cukup efektif dalam mempengaruhi behaviorisme anak terbukti dengan bobot 660 poin dari target maksimal 700 poin.

2. Penyusunan rencana siklus 2 pada kelompok A PG 2

Pelaksanaan tindakan mengacu pada pijakan lingkungan yang dipersiapkan guru pada tahapan main. Pada tanggal 13 September 2016 pijakan lingkungan yang disediakan guru adalah:

a. Meronce huruf hijaiyah, alat roncean, kartu peraga, dan tali dari benang kong.

b. Gerak lagu shalawat badar dan lagu rukun iman dengan gerakan senam otak.

c. Mewarnai huruf hijaiyah dan angka arab, alat spidol dan kertas

Pada tanggal 27 September 2016 pijakan lingkungan yang disipkan guru adalah:

a. Menulis angka 3 arab dengan alat kertas dan pensil.

b. Menjiplak bentuk buah bertuliskan a, ba, dengan alat kertas, lem dan puzzle

Pada tanggal 11 Oktober 2016, pijakan lingkungan yang disiapkan guru adalah:

a. Menulis huruf arab ja, alat pensil dan kertas

b. Menempel huruf arab ja, kha, kho dengan alat kertas, lem

c. Mencari hurf hijaiyah, dengan alat peraga huruf.

Hasil observasi dan pencatatan data siklus 2 berisi tentang lembar penilaian pada anak atau rangkuman penilaian anak selama 2 bulan kedua yaitu bulan September dan Oktober pada jadwal sentra Iman Taqwa. Guru melakukan penilaian hasil dari proses pembelajaran tentang pesan dakwah yang dikemas dalam sentra Iman Taqwa dalam aktifitas main. Guru menyediakan pijakan main sesuai capaian RPPH (Rencana Pelaksanaan Program Harian). Hasil penilaian didokumentasikan dalam Weekly Raport ( Laporan kegiatan mingguan). Adapun prosentase hasil belajar anak diakumulasi pada tabel prosentase akumulasi hasil belajar anak. kelompok A $\operatorname{Pg} 2$.

Tabel 6. Prosentase Hasil Belajar Anak Kelompok A Pg 2

\begin{tabular}{|l|c|c|c|}
\hline \multirow{2}{*}{\multicolumn{1}{|c|}{ Indikator }} & \multicolumn{3}{c|}{ Nilai (\%) } \\
\cline { 2 - 4 } & Baik & Cukup & Kurang \\
\hline Hafal dua kalimah Syahadat & 100 & - & - \\
\hline Mengetahui gerakan sholat & 90 & 10 & - \\
\hline $\begin{array}{l}\text { Mengenal huruf hijaiyah dan } \\
\text { angka arab }\end{array}$ & 100 & - & - \\
\hline $\begin{array}{l}\text { Taat pada orang tua dan bu } \\
\text { guru }\end{array}$ & 90 & - & - \\
\hline $\begin{array}{l}\text { Sayang pada teman dan mau } \\
\text { berbagi dengan teman }\end{array}$ & 90 & 10 & - \\
\hline Hafal rukun Islam & 100 & - & - \\
\hline
\end{tabular}


Temuan sementara bahwa aktifitas main yang dikemas dalam pembelajaran sentra Iman Taqwa kelompok A PG 2 cukup efektif dalam mempengaruhi behaviorisme anak terbukti dengan bobot 670 poin dari target maksimal 700 poin.

3. Penyusunan rencana silkus 2 pada kelompok B PG 3

Pelaksanaan tindakan mengacu pada pijakan lingkungan yang disiapkan guru pada tahapan main. Pada tanggal 13 september 2016 pijakan lingkungan yang disediakan guru adalah:

a. Meronce huruf hijaiyah, alat yang digunakan roncean, kartu peraga, dan benang kong.

b. Gerak lagu shalawat badar dan lagu rukun Islam dengan melakukan gerakan senam otak.

c. Mewarnai huruf hijaiyah dan angka arab. Alat yang digunakan kertas, spidol warna, dan krayon.

Pada tanggal 27 September 2016 pijakan lingkungan yang disediakan guru adalah:

a. Mencocokkan huruf arab ja, kha, kho, dengan alat kertas dan pensil.

b. Menulis angka tiga arab, alat kertas dan pensil.

c. Menjiplak bentuk buah-buahan bertuliskan huruf arab a, ba, dengan alat kertas, lem dan puzzle.

Pada tanggal 11 Oktober 2016 pijakan lingkungan yang disediakan guru adalah:

a. Menulis huruf arab ja, dengan alat pensil dan kertas.

b. Menempel huruf arab ja, kha, kho, alat kertas dan lem.

c. Mencari huruf hijaiyah.

Tabel 7. Prosentase Hasil Belajar Anak Kelompok A Pg 3

\begin{tabular}{|l|c|c|c|}
\hline \multirow{2}{*}{\multicolumn{1}{|c|}{ Indikator }} & \multicolumn{2}{c|}{ Nilai (\%) } \\
\cline { 2 - 4 } & Baik & Cukup & Kurang \\
\hline $\begin{array}{l}\text { Hafal dua kalimah } \\
\text { Syahadat }\end{array}$ & 100 & - & - \\
\hline Mengetahui gerakan sholat & 100 & 20 & 10 \\
\hline $\begin{array}{l}\text { Mengetahui arti puasa dan } \\
\text { bisa mempraktekkannya }\end{array}$ & 70 & - & - \\
\hline $\begin{array}{l}\text { Mengenal huruf hijaiyah } \\
\text { dan angka arab }\end{array}$ & 100 & - & - \\
\hline $\begin{array}{l}\text { Taat pada orang tua dan } \\
\text { bu guru }\end{array}$ & 100 & 5 & 5 \\
\hline $\begin{array}{l}\text { Sayang pada teman dan } \\
\text { mau berbagi dengan teman }\end{array}$ & 90 & - & - \\
\hline Hafal rukun Islam & 100 & - & \\
\hline
\end{tabular}


Temuan sementara bahwa aktifitas main yang dikemas dalam pembelajaran sentra Iman Taqwa kelompok B PG 3 cukup efektif dalam mempengaruhi behaviorisme anak terbukti dengan bobot 660 poin dari target maksimal 700 poin.

4. Penyusunan rencana silkus 2 pada kelompok B PG 4

Pelaksanaan tindakan mengacu pada pijakan lingkungan yang disiapkan guru pada tahapan main.

Pada tanggal 7 September 2016 pijakan lingkungan yang disediakan guru adalah:

a. Menulis huruf dan angka arab, dengan alat kertas dan pensil.

b. Kolase, alat kertas, kain perca dan lem.

c. Mewarnai, alat yang digunakan kertas, pensil dan krayon.

Pada tanggal 5 Oktober 2016 pijakan lingkungan yang disediakan guru adalah:

a. Menulis, alat yang digunakan kertas dan pensil.

b. Menebak, alat yang digunakan puzzle dan huruf hijaiyah.

c. Menempel, alat yang digunakan geometri, kertas dan lem.
Pada tanggal 19 Oktober 2016, pijakan lingkungan yang disediakan guru adalah:

a. Melukis, alat yang kertas, pensil dan krayon.

b. Menjepit, alat yang digunakan jepitan baju, kertas huruf, benang kong.

c. Membaca, alat yang digunakan qira'ati jilid pra.

Hasil observasi data siklus 2 berisi lembar penilaian anak atau rangkuman penilaian anak selama dua bulan terakhir terdapat 6 aspek/indikator yang berkaitan dengan pesan dakwah yang dapat meningkatkan behaviorisme anak melalui kegiatan sentra iman taqwa. Guru melakukan penilaian hasil dari proses pembelajaran tentang pesan dakwah yang dikemas dalam sentra Iman Taqwa dalam aktifitas main. Guru menyediakan pijakan main sesuai capaian RPPH (Rencana Pelaksanaan Program Harian). Hasil penilaian didokumentasikan dalam Weekly Raport ( Laporan kegiatan mingguan). Adapun prosentase hasil belajar anak diakumulasi pada tabel prosentase akumulasi hasil belajar anak. kelompok B $\operatorname{Pg} 4$.

Tabel 8. Prosentase Akumulasi Hasil Belajar Anak Kelompok b pg 4

\begin{tabular}{|l|c|c|c|}
\hline \multicolumn{1}{|c|}{ Indikator } & \multicolumn{3}{c|}{ Nilai (\%) } \\
\cline { 2 - 4 } & Baik & Cukup & Kurang \\
\hline Hafal dua kalimah Syahadat & 100 & - & - \\
\hline Mengetahui gerakan sholat & 100 & - & 10 \\
\hline $\begin{array}{l}\text { Mengetahui arti puasa dan } \\
\text { mempraktekkannya }\end{array}$ & 80 & - & - \\
\hline $\begin{array}{l}\text { Mengenal huruf hijaiyah dan } \\
\text { angka arab }\end{array}$ & 100 & 10 & \\
\hline Taat pada orang tua dan bu guru & 90 & 10 & \\
\hline $\begin{array}{l}\text { Sayang pada teman dan mau } \\
\text { berbagi dengan teman }\end{array}$ & 90 & - & - \\
\hline Hafal rukun Islam & 100 & & \\
\hline
\end{tabular}


Temuan sementara bahwa aktifitas main yang dikemas dalam pembelajaran sentra Iman Taqwa kelompok B PG 4 cukup efektif dalam mempengaruhi behaviorisme anak terbukti dengan bobot 660 poin dari target maksimal 700 poin.

\section{SIMPULAN}

Pesan dakwah pada anak usia dini yang dikemas melalui penciptaan lingkungan main berbasis sentra pada sentra Iman Taqwa cukup efektif terbukti dalam penelitian yang menggunakan pendekatan tindakan kelas dengan langkah 2 siklus. Siklus 1 menunjukkan hasil yang dicapai pada penilaian behaviorisme anak dengan indikator; hafal dua kalimah syahadat, mengetahui gerakan sholat, mengenal huruf hijaiyah dan angka arab, taat pada keduaorang tua, sayang pada teman dan mau berbagi dengan temandan hafal rukun Islam menunjukkan: pada kelompok A PG 1 tingkat pencapaian anak yang mampu memahami dan mempraktikkan pesan dakwah yang dikemas dalam pembelajaran sentra Iman taqwa menunjukkan hasil $88 \%$ dari $100 \%$ yang di targetkan. Pada kelompok A PG 2 menunjukkan hasil 88\% dari 100\% yang ditargetkan. Kelompok B PG 3 menunjukkan hasil 93\% dari 100\% yang ditargetkan. Dan pada kelompok B PG 4 menunjukkan hasil 96,5\% dari 100\% yang ditargetkan.

Sedangkanhasilskoryang dicapai pada siklus 2 tentang penilaian anak behaviorisme anak melalui kegiatan main dengan indikator hafal dua kalimah syahadat, mengetahui gerakan sholat, mengetahui arti puasa dan bisa mempraktekkannya, mengenal huruf hijaiyah dan angka arab, taat pada kedua orang tua, sayang teman dan mau berbagi dengan teman serta hafal rukun Islam menunjukkan hasil; tingkat pencapaian anak yang mampu memahami dan mempraktekkan pesan dakwah yang dikemas dalam pembelajaran sentra Iman Taqwa pada siklus 2 adalah: Pada kelompok A PG 1 skor yang dihasilkan adalah 94\% dari $100 \%$ yang ditargetkan, kelompok A PG 2 skor yang dihasilkan 95\% dari 100\% yag ditargetkan, kelompok PG 3 skor yang dihasilkan adalah $94 \%$ dari 100\% total skor yang ditargetkan, dan pada kelompok B PG4 skor yang dihasilkan 94\% dari 100\% skor yang ditargetkan.

Paparan tersebut diatas menunjukkan hasil penilaian terhadap kedua siklus yang telah dilakukan menunjukkkan bahwa pesan dakwah yang dikemas dalam pembelajaran anak usia dini berbasis sentra pada pembelajaran sentra Iman Taqwa cukup efektif meningkatkan behaviorisme anak. 


\section{DAFTAR PUSTAKA}

Aziz, Ali, Moh, 2004, Ilmu Dakwah, Jakarta, Kencana

Asmawati,Luluk, 2014, Perencanaan Pembelajaran PAUD, Bandung, PT Remaja Rosdakarya

Harist, Busyairi, 2006, Dakwah Kontekstual, Yogyakarta, Pustaka Pelajar

Nadhiroh, 2015, Penelitian Tindakan Kelas,-.-.,-..-

Istikhaili, Fitri, 2011, Neurosains Dalam Pembelajaran, Semarang, IKIP VETERAN Semarang

Khalwah, Movi, 2011, Metodologi Pengembangan Kreatifitas AnakUsia Dini, Semarang

Martani, Wisjnu, 2012,"Metode Stimulasi dan Perkembangan Emosi", Jurnal Psikologi, 1 (Juni),112-120

Putra, Nusa,et all, 2013, Penelitian Kualitatif Paud, Jakarta, Rajawali Press

Sari, Yulia, "Manajemen Pembelajaran Sentra dan Lingkaran Pada PAUD Subulussalam Kota Banda Aceh", Jurnal Pascasarjana Universitas Syiah Kuala,---- (November), 44

Susanto, Ahmad.2011, Perkembangan Anak Usia Dini: pengantar dalam berbagai aspeknya, Kencana Prenada Media Group

Setiawan, Rizky, 2014, Mudahnya Penelitian Tindakan Kelas, Cirebon, Eduvision Publishing,

Shofwan, Imam, 2012, Konsep Dasar PAUD, Semarang, IKIP VETERAN Semarang Suyadi, 2014, Teori Pembelajaran Anak Usia Dini, Bandung, PT Remaja Rosdakarya
Tedjasaputra, Mayke S., 2007, Bermain, Mainan, dan Permainan, Jakarta,PT. Gramedia

Ulfah, Maulida, 20012, Modul Kebutuhan Anak Usia Dini II, Yogyakarta

Yusuf, Syamsu, Juntika, Nurikhsan, 2013, Teori Kepribadian, Bandung, PT Remaja Rosdakarya

Wulan, Ratna, 2011, Mengasah Kecerdasan Pada Anak, Pustaka Pelajar, Yogyakarta 